\title{
Actual and perceived impacts of tobacco regulation on restaurants and firms
}

\author{
Pierre-Yves Crémieux, Pierre Ouellette
}

\begin{abstract}
Objective-To examine the actual and anticipated costs of a law regulating workplace smoking and smoking in restaurants, taking into consideration observed and anticipated infrastructure costs, lost productivity, increased absenteeism, and loss of clientele.

Setting and design-A survey of 401 Québec restaurants and 600 Québec firms conducted by the Québec Ministry of Health before the enactment of the law was used to derive costs incurred by those who had already complied and anticipated by those that did not.

Results-Direct and indirect costs associated with tobacco regulation at work and in restaurants were minimal. Annualised infrastructure costs amounted to less than $0.0002 \%$ of firm revenues and $0.15 \%$ of restaurant revenues. Anticipated costs were larger and amounted to $0.0004 \%$ of firm revenues and $0.41 \%$ of restaurant revenues. Impacts on productivity, absenteeism, and restaurant patronage were widely anticipated but not observed in currently compliant establishments.

Conclusion-Firms and restaurants expected high costs to result from strict tobacco regulation because of infrastructure costs, decreased productivity, and decreased patronage. That none of these were actually observed suggests that policy makers should discount industry claims that smoking regulations impose undue economic hardship.

(Tobacco Control 2001;10:33-37)
\end{abstract}

Keywords: regulation; firms; restaurants; costs; survey

The rapid decline in per capita tobacco consumption in Canada since the early 1970 s has slowed in part because the government has lowered tobacco taxes in response to contraband, despite the high costs of tobacco

Department of

Economics, Université du Québec à Montréal, Montréal, Québec, Canada

P-Y Crémieux

P Ouellette

Correspondence to: Pierre Cremieux, Analysis Group/Economics, One Brattle Square, 5th Floo Cambridge, MA 02138,

USA

pcremieux@analysisgroup.com

Received 8 January 2000 and in revised form

Accepted 29 July 2000 smoking within their establishments if they considered the required changes too expensive to implement.

This research has two goals:

- to determine the actual and perceived effect of regulation requiring compliant infrastructure on firms' costs, and to assess the impact of such regulation on employee productivity and absenteeism;

- to estimate the actual and perceived effect of tobacco regulation on the costs of bringing restaurants' infrastructures to compliance with the law and on patronage.

\section{Regulating on-the-job smoking}

Increased efforts to control workplace smoking over the last decade have been generally successful $1^{11-14}$ and should be of particular interest to Canadian employers in the light of results suggesting that increased annual absenteeism costs and loss in productivity induced per smoking employee totals C $\$ 2403 .{ }^{8}$ Despite these findings, however, many firms do not regulate smoking on their premises because of concerns about infrastructure costs and short run losses in productivity and absenteeism.

We rely on firms that have already adopted smoking bans (actual costs are observed) as a benchmark from which to assess the perceived costs of those that do not have such policies in place. Of course, systematic differences between the two groups might exist. For example, firms that built ventilated smoking areas might be those for which associated costs were the lowest. If so, some of the observed differentials might be real. It is more likely, however, that tobacco companies' active propaganda has led firms without such policies in place to overstate expected costs.

\section{Regulating smoking in restaurants}

Significant research has also investigated the effect of tobacco regulation in the restaurant industry, both in the USA and elsewhere. ${ }^{15-23}$ Research has shown that air quality is poor in smoking restaurants, with levels of environmental tobacco smoke 1.6-2.0 times higher than in office workplaces, and in bars, with levels 3.9-6.1 times higher.

Regulatory efforts aimed at the restaurant industry have been contentious, however. When regulation is voluntary, restaurateurs are reluctant to impose smoking bans unilaterally for fear of losing smoking customers. ${ }^{24}$ This defensive posture does not appear to be warranted in view of studies showing that consumers might preferentially patronise nonsmoking establishments. ${ }^{151625}$ designated areas. Restaurant owners and employers could also choose to simply forbid 
Even uniformly applied laws have met resistance, with restaurateurs worried that smokers would choose to patronise restaurants less frequently overall, and that smoking tourists might choose to visit other locales more hospitable to smokers. However, numerous studies have suggested that when a smoking ban is uniform throughout a geographic area (city, state, province, etc), the effect of regulation seems non-existent or even favourable to total sales and employment in the area. ${ }^{17-21} 23$

As for firms, differences between actual and anticipated costs may result both from real differences in restaurant characteristics (for example, different clientele or different infrastructure) or from inaccurate anticipations from restaurants without policies.

\section{The case of Québec}

Because smoking prevalence in Québec is one of the highest in North America, the percentage of firms affected by a legal change and the potential costs of absenteeism and lost productivity should provide an upper bound on regulatory impact anywhere in North America.

The period during which the survey underlying this research was conducted was characterised by a modest level of public lobbying activity on the part of tobacco companies. We do not know whether or to what extent restaurants or firms in Québec were influenced by this lobbying to change their opinions about the potential costs of the proposed legislation in this survey, which could have led restaurant owners and firm managers to overstate the anticipated impact of the law. To neutralise such an effect, we designed the survey to ask restaurants and firms both about anticipated costs (for those which do not have a policy) and actual costs (for those already in compliance with a more objective assessment of incurred costs).

\section{Method}

Because of concerns from both restaurant owners and firms about the economic impact of a law regulating on-the-job tobacco use and smoking in restaurants, the Québec government mandated us to design, direct, and analyse three surveys of businesses in the province: 400 firms; 200 large firms with 200 or more employees; and 401 restaurants. Our goal was to examine both observed and perceived impacts of the new tobacco regulation. The polling firm SOM, Inc conducted the surveys by telephone between 23 and 30 May 1997.

No information is available on the profile of the firms and restaurants that answered the interviewers compared to those that did not. However, the high rate of response among firms that were reached decreases the probability of selection bias. Another concern is the accuracy of responders' estimates of costs or recall on incurred costs. In all cases, responses were based on the interviewees' recall rather than a review of the firm's financial records; the positions of the responders within the companies are detailed below.
SURVEY OF ALL FIRMS

A random sample was drawn of 400 commercial or institutional firms from a directory of all Québec firms. These included all private sector firms as well as semi-public entities such as hospitals, financial institutions owned by the government, etc. It excluded, however, all non-commercial institutions such as provincial and federal governments or schools. Of 966 firms called, 452 were reached of which 400 answered-a response rate of $88 \%$. Among the responders, 25\% were owners of the firm, $11 \%$ were presidents, $3 \%$ were vice presidents, $23 \%$ were directors, $7 \%$ were administrators, and $14 \%$ were accountants. The remaining $17 \%$ of respondents had other titles or did not report.

SURVEY OF LARGE FIRMS

We conducted a second survey of 200 large firms (200 employees or more) drawn randomly from a directory of the 1000 largest firms in Québec. We sampled large firms independently of smaller firms because different effects might be observed, and because of the large firms' disproportionate effect on employment. Of 352 firms called, 218 answered the telephone of which 200 agreed to participate in the study for a response rate of $92 \%$. Two per cent of responders were owners of the firm, $4 \%$ were presidents, $8 \%$ were vice presidents, $32 \%$ were directors, $24 \%$ were administrators, and $13 \%$ were accountants. The remaining $17 \%$ of responders had other titles or did not respond.

SURVEY OF RESTAURANTS

A final survey drew a random sample of 401 restaurants from a directory of 12000 Québec restaurants. Of 737 restaurants called, 440 were reached and 401 responded, for a response rate of $91 \%$. Among the responders, $58 \%$ were owners, $5 \%$ were co-owners, $26 \%$ were managers, and $4 \%$ were assistant managers. The remaining $7 \%$ of responders had other titles.

\section{Results}

ACTUAL AND PERCEIVED IMPACT OF REGULATING ON-THE-JOB TOBACCO USE

Policies regulating on-the-job tobacco use

Forty nine per cent of the representative sample of all firms and $68 \%$ of large firms already had a policy regulating tobacco $\left(\chi^{2}=18.72, p=0.001\right)$. Large firms were also more likely to have policies in place that would be compliant under the new law $\left(\chi^{2}=5.59\right.$, $\mathrm{p}=0.018) ; 34 \%$ of all firms and $45 \%$ of large firms were smoke free or offered ventilated smoking areas.

Firms without policies restrictive enough to satisfy the proposed law (66\% of all firms and $56 \%$ of large firms) were then asked how they would choose to comply with the law. Of this subset, $29 \%$ of all firms opted for smoke free status and $55 \%$ would build a ventilated smoking area. Among large firms, 50\% would become smoke free and $21 \%$ would build a smoking area. This implies that the law would impose no direct costs on over $53 \%$ of all firms (and $72 \%$ of large firms) either because they 
Table 1 Actual and anticipated cost of designated smoking area

\begin{tabular}{|c|c|c|c|c|c|}
\hline & $\begin{array}{l}C \$ 0-1000 \\
\%(95 \% C I)\end{array}$ & $\begin{array}{l}C \$ 1000-5000 \\
\%(95 \% C I)\end{array}$ & $\begin{array}{l}C \$ 5000-10000 \\
\%(95 \% C I)\end{array}$ & $\begin{array}{l}\text { Over C\$10000 } \\
\%(95 \% C I)\end{array}$ & $\begin{array}{l}\text { Unknown } \\
\%(95 \% C I)\end{array}$ \\
\hline \multicolumn{6}{|l|}{ All firms ${ }^{\star}$} \\
\hline Actual $(n=42)$ & 64 (49 to 79$)$ & 12 (2 to 22$)$ & 0 & 0 & 24 (11 to 37$)$ \\
\hline Anticipated $(\mathrm{n}=77)$ & 47 (36 to 58$)$ & 25 (15 to 35$)$ & 7 (1 to 13$)$ & 0 & $22(13$ to 31$)$ \\
\hline \multicolumn{6}{|l|}{ Large firmst } \\
\hline Actual $(n=50)$ & $38(25$ to 51$)$ & $24(12$ to 36$)$ & $2(0$ to 6$)$ & 16 (6 to 26$)$ & $20(9$ to 31$)$ \\
\hline Anticipated $(n=61)$ & $23(12$ to 34$)$ & 25 (14 to 36$)$ & $10(2$ to 18$)$ & $8(1$ to 15$)$ & $34(22$ to 46$)$ \\
\hline
\end{tabular}

$\star$ Test of difference in proportions between all firm actual samples: $\chi^{2}=6.54, p=0.088$.

†Test of difference in proportions between large firm samples: $\chi^{2}=8.25, \mathrm{p}=0.083$.

already conform with the law or because they would opt to forbid smoking rather than incur costs to build designated smoking areas.

Construction costs for closed and ventilated smoking areas

Assuming that actual costs fall at the median point of the chosen range (C\$0-1000, C\$1000-5000, C\$5000-10 000, C\$10 000+), large firms with ventilated smoking areas reported average building costs for a ventilated smoking area of $C \$ 3325$ per site. Whether this was a cost per site or per firm was ambiguous; however, half of the firms had one or two sites and had therefore incurred costs below C $\$ 6650$. In $90 \%$ of the cases, these firms had fewer than 15 sites. In the representative sample, compliant firms reported an average non-recurrent cost of establishing a designated smoking area of $\mathrm{C} \$ 891$, and average annual revenues of $\mathrm{C} \$ 5.4$ million.

Firms without smoking areas but expecting to build one anticipated greater costs than those incurred by currently compliant firms (table 1). For example, large firms in that category anticipated average costs of $\mathrm{C} \$ 3675$, $11 \%$ higher than was incurred by compliant firms. For the sample of representative firms, the anticipated average cost was C $\$ 1815$, roughly twice the cost incurred by compliant firms. Both differences, though, were marginally insignificant (large firms $\chi^{2}=8.25$, $\mathrm{p}=0.083$; all firms $\left.\chi^{2}=6.54, \mathrm{p}=0.088\right)$.

Compliance and impact on employee performance and absenteeism

Large firms with some form of tobacco control policy reported $100 \%$ compliance by their employees; $94 \%$ of the representative reported compliance rates of over $75 \%$, and $76 \%$ reported full compliance.

In both surveys, firms that maintained a tobacco control policy observed virtually no induced impact on employee performance or absenteeism (table 2). A larger percentage of non-compliant firms expected some induced impact, whether positive or negative, on performance and absenteeism. Firms expected both a sharper decrease in absenteeism and greater productivity losses than reported by compliant firms. A majority of firms still anticipated no impact on employee behaviour.

ACTUAL AND PERCEIVED IMPACT OF SMOKING REGULATION IN QUÉBEC RESTAURANTS

Restaurant owner regulatory preferences

A majority of restaurant owners $(65 \%)$, both with and without a policy in place $\left(\chi^{2}=5.47\right.$, $\mathrm{p}=0.065)$, preferred a law allowing them to build closed ventilated areas rather than a sweeping smoke free regulation, the option preferred by $28 \%$, with $7 \%$ not responding. However, in response to such a law, most restaurants would still choose not to build a smoking section. A majority of restaurant owners without a smoking section did not intend to build one mostly because of financial or technical reasons. There are important differences among restaurant categories. For example, approximately $80 \%$ of fast food restaurants would not build smoking sections irrespective of the law. For fast food restaurants as for others, technical and financial difficulties are most often cited as reasons not to build smoking sections.

\section{Costs of building closed ventilated smoking} sections

The construction costs for a closed ventilated area anticipated by restaurants already planning to install one and those that would install one only if required to by law were found to be significantly higher than the costs actually incurred by restaurant owners $\left(\chi^{2}=18.70, \mathrm{p}=0.017\right)$. Only 14 sampled restaurants were equipped with a closed ventilated smoking section, and nine expected to build one within the next two years irrespective of the law. Assuming that costs in each reporting category $(C \$ 0-1000, C \$ 1000-5000$, $\mathrm{C} \$ 5000-10000,>\mathrm{C} \$ 10000)$ were at the median point, compliant restaurants incurred average construction costs of C $\$ 1591$. Restaurants intending to build irrespective of the law expected to incur costs averaging C $\$ 2563$. Finally, the 109 restaurant owners who would

Table 2 Actual and anticipated impact of tobacco control policies on productivity and absenteeism in firms with no current policies

\begin{tabular}{|c|c|c|c|c|c|c|c|c|}
\hline & \multicolumn{4}{|c|}{ Employee performance, \% $(95 \%$ CI) } & \multicolumn{4}{|c|}{ Employee absenteeism, \% (95\% CI) } \\
\hline & Increase & Decrease & Unchanged & Unknown & Increase & Decrease & Unchanged & Unknown \\
\hline \multicolumn{9}{|l|}{ All firms } \\
\hline Actual $(n=42)$ & $7(56$ to 84$)$ & $4(0$ to 10$)$ & $79(67$ to 91$)$ & $10(1$ to 19$)$ & $2(0$ to 6$)$ & $2(0$ to 6$)$ & 86 (76 to 96$)$ & $9(0$ to 18$)$ \\
\hline Anticipated $(n=77)$ & $8(2$ to 14$)$ & $16(8$ to 24$)$ & 68 (58 to 78$)$ & $8(2$ to 14$)$ & $6(1$ to 11$)$ & $8(71$ to 89$)$ & 78 (69 to 87$)$ & $8(2$ to 14$)$ \\
\hline \multicolumn{9}{|l|}{ Large firms } \\
\hline Actual $(n=50)$ & $6(46$ to 74$)$ & $6(0$ to 13$)$ & $62(49$ to 75$)$ & $26(14$ to 38$)$ & $8(0$ to 16$)$ & $4(26$ to 54$)$ & $71(58$ to 84$)$ & $17(7$ to 27$)$ \\
\hline Anticipated $(n=61)$ & $14(5$ to 23$)$ & $24(13$ to 35$)$ & $54(41$ to 67$)$ & $8(1$ to 15$)$ & $6(0$ to 12$)$ & $14(5$ to 23$)$ & $72(61$ to 83$)$ & $8(1$ to 15$)$ \\
\hline
\end{tabular}


Table 3 Restaurant owners' revenue expectations following regulation

\begin{tabular}{|c|c|c|c|c|}
\hline & $\begin{array}{l}\text { Increase in revenues } \\
\%(95 \% \mathrm{CI})\end{array}$ & $\begin{array}{l}\text { Decrease in } \\
\text { revenues } \\
\%(95 \% \text { CI })\end{array}$ & $\begin{array}{l}\text { Revenues unchanged } \\
\%(95 \% \text { CI) }\end{array}$ & $\begin{array}{l}\text { Do not know/ no } \\
\text { answer } \\
\%(95 \% \text { CI) }\end{array}$ \\
\hline Open smoking section $(n=124)$ & $3(0$ to 6$)$ & $14(8$ to 20$)$ & 75 (67 to 83$)$ & $8(3$ to 13$)$ \\
\hline Closed smoking section $(n=7)$ & 0 & 0 & $86(60$ to 100$)$ & $14(0$ to 40$)$ \\
\hline Closed ventilated section $(n=14)$ & 0 & 0 & $86(67$ to 100$)$ & $14(0$ to 33$)$ \\
\hline Total $(n=145)$ & $3(0$ to 5$)$ & $12(6$ to 17$)$ & $77(70$ to 83$)$ & $9(4$ to 14$)$ \\
\hline Restaurants without policy $(n=256)$ & $5(2$ to 7$)$ & $60(54$ to 66$)$ & $24(19$ to 29$)$ & $11(7$ to 15$)$ \\
\hline
\end{tabular}

Test of difference in proportions between samples for any policy versus no policy: $\chi^{2}=110.52, p=0.001$.

build only in response to the law anticipated an average non-recurrent cost of C $\$ 4330$. This cost is 2.7 times higher than that actually incurred by those already in compliance, and 1.7 times higher than that expected by those who would build irrespective of the law.

Potential impact on revenues

Restaurant owners' responses about expected revenues after law implementation (increased, decreased, unchanged, or no answer) varied significantly according to their current smoking policy $\left(\chi^{2}=110.52, \quad \mathrm{p}=0.001\right)$. Eighty per cent of restaurant owners with some form of tobacco regulation in place did not anticipate a decrease in revenues as a result of the government regulation (table 3). None of the 21 restaurant owners in compliance expected decreased revenues. In contrast, $60 \%$ of restaurants without a policy believed that revenues would fall.

\section{Discussion}

As a result of persistently high per capita tobacco consumption and contraband in response to increased tax rates, the government of Québec enacted a law regulating, among other things, on-the-job tobacco use and smoking in restaurants. Before the law's enactment, we designed, administered, and analysed a survey to firms and restaurants to determine the perceived and actual economic impact such a law was likely to have.

The survey of firms shows that despite one of the highest smoking rates in North America, $53 \%$ of all Québec firms and $72 \%$ of large firms will experience no additional direct costs either because they already comply with the proposed legislation, or because they intend to forbid smoking, thereby avoiding any construction costs for smoking areas. Non-recurrent annualised building costs for separate ventilated smoking areas are small in absolute terms and in both surveys represent on average no more than $0.0002 \%$ of average annual revenue. Since average profit rates vary across industries, it is difficult to determine what percentage of profits these costs might represent. However, even assuming a no-risk profit rate of $5 \%$, the non-recurrent annualised cost of building smoking areas would be, on average, no greater than $0.003 \%$ of annual profits (with a hypothesis of $10 \%$ interest rates).

The survey administered to restaurants suggests a major preference for a policy authorising smoking sections rather than a blanket prohibition on smoking, and indicates that few restaurants are currently in compliance with the proposed legislation. For restaurants, annualised non-recurrent costs of compliance with the law were less than $0.15 \%$ of annual revenues or $3 \%$ of profits. The anticipated building costs by non-compliant firms were over twice that actually incurred by currently compliant establishments. Nonetheless, even these possibly overstated tax deductible non-recurrent costs remain below 3\% of profits.

Because of lack of data we have not examined policy enforcement costs. However, the high compliance rate at firms with existing policies indicates that employees typically comply with limitations on tobacco use. This results in part from the presence, in firms as elsewhere, of a majority of non-smokers.

Throughout both surveys, a pronounced difference existed between the responses of firms and restaurants that had already voluntarily instituted bans and those that had not, both with respect to costs (incurred or anticipated) and attitudes about the law. One possible explanation for this difference might be self selection. For example, firms that had already built ventilated smoking areas might be those for which such facilities were most easily or cheaply built. Restaurants that already had smoking bans in place might cater to a different clientele than those that did not. Hence, some of the difference between realised and anticipated costs might be real. This would also help explain the more accurate estimates provided by the large firms compared to smaller ones. Most large firms, including those without existing facilities, enjoy greater flexibility in their decision to locate any amenities. This will yield costs similar to those actually incurred by firms in compliance. On the contrary, smaller non-compliant firms might have significant space constraints which make such building more difficult.

Another reason for the discrepancy, however, might be misperception on the part of the non-adopters. A majority of respondents not currently in compliance feared a negative impact on sales, despite the opposite results found by compliant Québec firms and by numerous studies in the literature. Lacking experience of a ban, perhaps these firms and restaurants were simply risk averse and overestimated the negative impact of a ban. Years of tobacco industry lobbying against workplace and restaurant smoking regulation might also have distorted their estimation. Indeed, tobacco companies have become increasingly active politically to defeat anti-smoking laws and ordinances, often retaining professional campaign and public relations firms and 
concealing their own involvement. ${ }^{26}$ This would explain, in part, a fear of the regulation that appears to lack empirical grounding.

Together, the results from surveys of both firms and restaurants show that even in a high smoking prevalence area such as Québec, a relatively strict law regulating smoking on-thejob and in restaurants is unlikely to have any major negative economic impact on either industry. It also shows that the experience of firms and restaurants already in compliance with the law is consistent with the literature and indicates no adverse effects, and that the expectations of non-compliant firms and restaurants are likely to be overstated. This suggests that private costs associated with strict tobacco laws, if any, are likely to be minimal in these two sectors.

We thank Susan Hoag and Matthew Gubens for helpful comments. We thank the Ministère de la Santé et des Services Sociaux of Québec for data and financial support.

1 Cunningham R. La guerre du tabac. Ottawa: Research Centre for International Development, 1996.

2 Hamilton VH, Levinton C, St-Pierre Y, et al. The effect of tobacco tax cuts on cigarette smoking in Canada. Can Med tobacco tax cuts on cigare

3 Single E, Robson L, Xie X, et al. The costs of substance abuse in Canada. Canadian Center on Substance Abuse, 1996.

4 Morin M, Kaiserman M, Leahy K. Mortalité régionale attribuable au tabagisme au Canada, 1989. Maladies Chroattribuable au tabagisme au Canada,
niques au Canada 1992;13:68-70.

5 Environmental Protection Agency. Respiratory effects of passive smoking: lung cancer and other disorders. Washington, DC: 2000

6 Taylor AE, Johnson DC, Kazemi H. Environmental tobacco smoke and cardiovascular disease. A position paper from the council on cardiopulmonary and critical care, American Heart Association. Circulation 1992;86:699702 .

7 Reynolds P. Epidemiologic evidence for workplace ETS as a risk factor for lung cancer among nonsmokers: specific risk estimates. Environ Health Perspec 1999;107(suppl 6):86572 .

8 Conference Board of Canada. Bilan de la consommation de tabac: les coûts de l'usage du tabac en milieu de travail. Ottawa: Conference Board of Canada, 1997.
9 Siegel M. Involuntary smoking in the restaurant workplace: a review of employee exposure and health effects. $¥ A M A$ a review of employe

10 Wells AJ. Passive smoking as a cause of heart disease. $7 \mathrm{Am}$ Coll Cardiol 1994;24:546-54

11 Brownson RC, Eriksen MP, Davis RM, et al. Environmental tobacco smoke: health effects and policies to reduce exposure. Ann Rev Public Health 1997;18:163-85.

12 Eriksen MP, Gottlieb NH. A review of the health impact of smoking control at the workplace. Am f Health Promotion 1998;13:83-104.

13 Farrelly MC, Evans WN, Sfekas AE. The impact of workplace smoking bans: results from a national survey. Tobacco Control 1999;8:272-7.

14 Glasgow RE, Cummings KM, Hyland A. Relationship of worksite smoking policy to changes in employee tobacco use: findings from COMMIT, community intervention trial for smoking cessation. Tobacco Control 1997;6(suppl 2):S44-8.

15 Shofield MJ, Considine R, Boyle C, et al. Smoking control in restaurants:the effectiveness of self-regulation in Australia. Am $\mathcal{F}$ Public Health 1993;83:1284-8.

16 Gallup. A Gallup Organization public opinion survey on New Yorkers' attitudes about smoke-free dining, 1994

17 Huang P, Tobias S, Kohout S, et al. Assessment of the impact of a $100 \%$ smoke-free ordinance on restaurant sales-West Lake Hills, Texas, 1992-1994. MMWR Morb Mortal Wkly Rep 1995;44:370-84.

18 Glantz SA, Smith LRA. The effect of ordinances requiring smoke-free restaurants on restaurant sales. Am $\mathcal{F}$ Public Health 1994;84:1081-5.

19 Glantz SA, Charlesworth A. Tourism and hotel revenues before and after passage of smoke-free restaurant ordinances. $\mathscr{F} A M A$ 1999;281:1911-18.

20 Hyland A, Cummings KM. Restaurant employment before and after the New York City Smoke-Free Air Act. Fournal of Public Health Management and Practice 1999;5:22-7.

21 Hyland A, Cummings KM. Restaurateur reports of the economic impact of the New York City Smoke-Free Air Act. Fournal of Public Health Management and Practice 1999; 5:37-42.

22 Hyland A Cummings KM, Wilson MP. Compliance with the New York City Smoke-Free Air Act. Fournal of Public Health Management and Practice 1999;5:43-52.

23 Bartosch WJ, Pope GC. The economic effect of smoke-free restaurant policies on restaurant business in Massachusetts. Fournal of Public Health Management and Practice 1999;5:53-62.

24 Jones K, Wakefield M, Turnbull DA. Attitudes and experiences fo restaurateurs regarding smoking bans in Adelaide, South Australia. Tobacco Control 1999;8:62-6.

25 Conference Board of Canada. The economic consequences of smoking prohibition in restaurants. Ottawa: Conference Board of Canada, 1996.

26 Traynor MP, Begay ME, Glantz SA. New tobacco industry strategy to prevent local tobacco control. FAMA 1993; 270:479-86. 